\title{
SABERES E SABEDORIA: \\ A POTENCIALIDADE DAS CIRCUNSTÂNCIAS NUM MANUAL DE EDUCAÇÃO DO SÉCULO XII
}

\author{
Armando Martins* \\ armandoalberto.martins@gmail.com
}

RESUMO: Várias obras do mestre parisiense, Hugo de S. Vítor (1096-1141), cónego regrante daquela abadia, eram conhecidas e estudadas nos mosteiros portugueses de S. Vicente de Fora de Lisboa e Santa Cruz de Coimbra, desde o século XIII. Assim, o breve tratado De Institutione Novitiorum, era destinado a formar os futuros regrantes nas tradições e costumes da Ordem de S. Agostinho. Não se trata de um mero texto espiritual, mas é também uma espécie de segunda aba de um díptico do Didascalicon, obra anterior. Pequeno manual de boas maneiras ou «arte de viver», tinha preocupações gerais de humanismo antropológico e cívico, regras de boa educação, entendidas como base do estado de perfeição da verdadeira vida religiosa cristã. Mas há que atender sempre às circunstâncias em que o processo decorre. Estas ideias, nascidas em França e transplantadas para o Portugal medieval continuaram a servir de guias de formação e chegaram, mais tarde, plasmadas na mentalidade dos regrantes no Brasil, como D. Thomaz da Encarnação, bispo de Olinda-Recife (1774-1784), homem culto e reformador da sua diocese.

PALAVRAS-CHAVE: Hugo de S. Vitor, ciência, disciplina, arte de ler, arte de viver.

É já hoje comum na investigação histórica medieval, de métodos renovados e território alargado, valorizar fontes textuais até há pouco desdenhadas ou tidas por menores, como manuais de disciplina clerical, opúsculos pedagógicos, hagiografias ou tratados de espiritualidade. A sua atenção levou os que cultivam a história cultural a repensar conceitos e a afinar termos do seu vocabulário, ou a interessar-se por outros domínios como os da antropologia e da sociologia, que os tornassem aptos a analisar e mesmo a explicar regras e códigos de comportamento ético e social na vida quotidiana do passado; aspectos de permanência ou de mudança de costumes e mentalidades; formas de tratamento do corpo e do espírito: domínios que vieram a mostrar-se traços fundamentais no esforço da civilização.

Escrevendo há uns vinte anos, Jacques Le Goff (1991) dizia:

\footnotetext{
* Doutor em História pela Universidade de Lisboa. Professor e membro-investigador do Centro de História da Universidade de Lisboa e acadêmico de número da Academia Portuguesa da História.
} 
Hoje, quando a história social está em crise porque acabou por tudo absorver, porque a sociedade nas suas realidades e nas suas representações está também em crise e que a crise epistemológica da sociologia que daí resulta tem tendência a minar as outras ciências ditas sociais, a começar pela história, a história cultural é o lugar onde se recompõe a história social (pp. 09-10).

O objectivo desta minha comunicação é, a partir de um manuscrito pedagógico medieval português, pertencente a uma instituição religiosa de Lisboa, mostrar como certos modelos de educação, desde o século XII, além de perseguirem ideais éticos, criaram códigos de boas maneiras e contribuíram para a formação do sistema de valores da sociedade ocidental de que ainda hoje somos devedores.

Lê-se na mais antiga biografia de Santo António de Lisboa (1195-1231), a Legenda Prima ou Assídua ${ }^{1}$, que o jovem Fernando Martins - era esse o seu nome de baptismo - depois de ter aprendido as primeiras letras na escola-catedral da cidade, recém conquistada aos mouros (1147), continuou a sua educação, durante dois anos, no vizinho mosteiro de S. Vicente de Fora, antes de passar para a também regrante canónica de S. Cruz, em Coimbra, então, a sede da corte régia e do governo de Portugal.

Foi em S. Vicente de Fora (fora da muralha da cidade), tendo cerca de quinze anos, que o jovem Fernando continuou os estudos, vestiu o hábito, foi noviço e professou, segundo a Regra de S. Agostinho, ingressando na comunidade canonical da cidade. Que teria ele ali estudado? De que obras e autores poderia dispor? Quem foram os seus mestres? Onde se teriam formado estes? Em suma, como foi feita a sua educação?

Um breve inventário de manuscritos da livraria de mão do mosteiro vicentino, redigido por volta de meados do século XIII, deixa-nos algumas pistas para poder responder àquelas perguntas. Trata-se de uma lista de livros (a que dificilmente poderemos chamar de 'catálogo da biblioteca'), que foi inserida no último fólio de um obituário do mosteiro de S. Cruz de Coimbra (Catálogo dos Códices da Livraria de Mão do Mosteiro de Santa Cruz de Coimbra na Biblioteca Pública Municipal do Porto, 1997, pp. 340-341) $)^{2}$ O rol dos livros da biblioteca de Lisboa passou despercebido aos estudiosos destas matérias durante muito tempo, até ser estudado e editado por Francisco da Gama Caeiro, em 1967, quando, na Faculdade de Letras da Universidade de Lisboa, fez o seu doutoramento em Filosofia (GAMA CAEIRO, 1967, pp. 31-37).

O citado inventário, longa lista, rica e variada de espécimes, inclui 60 items manuscritos, com obras da Sagrada Escritura e seus comentários, homiliários, lecionários, antifonários, saltérios, literatura monástica e patrística, autores de gramática 
como Prisciano e Papias, clássicos como Ovídio, as Histórias de Paulo Orósio, muitas obras de Direito, glosas várias para o ensino da Teologia e vários autores modernos nestes domínios: Hugo de S. Victor de Paris (+1141), Graciano de Bolonha (+1160), Hugo de Folieto (+1174) e um livro de Sentenças, sem autor indicado, mas que bem podia ser do famoso mestre parisiense e depois, seu bispo, Pedro Lombardo $(+1160)$. A obra indicada, do mestre e fundador da escola vitorina de Paris, Hugo, era De Institutione Novitiorum: fora escrita por volta de 1130 e era nas canónicas dos Regrantes o já prestigiado manual para a educação e formação dos noviços, futuros regrantes. Obra pequena, mas pioneira e particularmente interessante para a história da educação e da cultura, mesmo para além da Idade Média, como mais adiante veremos.

Notemos ainda, como observação curiosa, que o 'catálogo' da biblioteca de S. Vicente de Lisboa, numa época em que não havia livrarias nem bibliotecas, e quando estas obras escritas eram tão raras como caras, incluía também uma secção de códices, que andavam emprestados na mesma cidade, na de Viseu e na de Coimbra, a instituições e a pessoas particulares. Ou seja, tratava-se de uma instituição cultural dinâmica, razoavelmente bem provida, actualizada e aberta, porque ousava deslocar para o exterior os seus códices, de obras antigas ou contemporâneas, e pô-los em circulação nas mãos de um maior número de leitores e estudiosos do que aqueles que a ela podiam acorrer. Ao menos desde o início desse século XIII, o mesmo acontecia em Coimbra: um documento desse mosteiro mostra-nos como, em 1207, 1218 e 1226, muitas obras da canónica (particularmente de medicina, astronomia e física) circulavam, emprestadas em Lisboa, e até mesmo ao mosteiro de S. Vicente (Catálogo dos Códices da Livraria de Mão do Mosteiro de Santa Cruz de Coimbra na Biblioteca Pública Municipal do Porto, 1997, p. 199; GAMA CAEIRO, 1967, p. 35) ${ }^{3}$.

É, igualmente, significativo, dada a brevidade do registo, o facto de o 'catálogo' de Lisboa não ser um códice independente mas se encontrar inserido num outro. Com efeito, o obituário de que falámos era um grosso volume de 92 fólios rígidos, numerados mais 6 folhas de papel. Parece ter pertencido ao mosteiro de Coimbra, tem sinais de muito uso e arquiva três assuntos muito distintos: o obituário propriamente dito (Obituarium Monasterii Sanctae Crucis) ou lista dos defuntos pelos quais a comunidade, diariamente, fazia sufrágios (fólios 1-90v); uma Notitia de Rendis (fl 91r), ou seja, uma lista de foros a receber, em morabitinos, pelo arrendamento de bens rurais da canónica; e, finalmente, o Inventário dos livros («Hii sunt libri ...»), fl 
92r. Bem à maneira da época, o registo e elenco das coisas materiais, coexistia, lado a lado, com as preocupações intelectuais e espirituais.

Segundo os autores da mais recente edição do catálogo da livraria medieval de S. Cruz de Coimbra, este códice encontra-se redigido em letra gótica cursiva e librária, a várias mãos, com iniciais caligrafadas a verde e vermelho e outra ornamentação rudimentar. A encadernação actual é obra de restauração, com a cobertura em pele castanha clara, tendo incisos em losango e cinco florões em cruz. A lombada em que se inscrevem cotas antigas (S. Cruz 84; LXXXIV; BPMP 707) está bastante deteriorada, certamente, devido ao muito uso que lhe foi dado (CCLS, 1997, p. 340).

Como a citada primeira biografia de S. António refere, feita a profissão religiosa em Lisboa, o jovem Fernando rumou para Coimbra, a fim de ali continuar a sua formação e preparação para a vida de sacerdote e regrante com as tarefas litúrgicas, pastorais e culturais que lhe competiam. Coimbra era, no princípio do século XIII, uma cidade em franca expansão e tinha um já muito conhecido e poderoso mosteiro de protecção régia e papal. A sua escola canonical de nível superior, a que acorriam muitos candidatos à vida regrante e ouvintes externos, rivalizava com a escola-catedral que ultrapassava em prestígio e fama dos seus mestres.

O mosteiro de Santa Cruz fora fundado em 1131, às portas da cidade, por um grupo culto, aberto e viajado de clérigos, dissidentes do cabido da sé local, onde avultavam D. Telo, D. Teotónio e D. João Peculiar que mais tarde seria bispo do Porto e arcebispo-metropolita de Braga. Convencidos da necessidade e urgência de reforma da vida religiosa, especialmente do clero, movia-os, no quadro de reforma gregoriana da Cristandade ocidental, o propósito de formarem uma comunidade, submetida à Regra de S. Agostinho e pautada pela austeridade de vida e pela pobreza evangélica, à maneira da primitiva Igreja, tal como já se fazia em vários pontos de além Pirenéus. Conseguiram para a sua instituição o apoio do jovem conde de Portucale que, por essa altura, abandonando Guimarães, acabava de se fixar na mesma cidade, julgada estratégica para os seus objectivos de conquista expansionista para Sul e autonomia política face ao reino de Leão e Castela. Os fundadores regrantes, para definirem o seu quadro jurídico, procuraram a anuência do bispo local e a aprovação do papa, objectivos que iriam conduzi-los a muitos, longos e dolorosos trabalhos, a fim de manterem o singular estatuto de vida que se propunham, mas que era entendido como afronta desafiadora e provocava a persistente rivalidade dos seus antigos confrades do cabido secular. 
Para melhor se enquadrarem no movimento europeu da reforma que procuravam, os Regrantes de Coimbra cedo enviaram alguns dos seus à modelar canónica de S. Rufo de Avinhão (provavelmente conhecida aquando de alguma das suas viagens a Roma ou à Terra Santa), a fim de estudarem, copiarem e trazerem para a cidade do Mondego os costumes da vida quotidiana e os livros essenciais da sua liturgia e espiritualidade (GAMA CAEIRO, 1967, p. 86) ${ }^{4}$.

As pesquisas efectuadas pelo professor Gama Caeiro e por mim próprio quando redigi, sobre este tema, a minha tese de doutoramento (MARTINS, 2003), provaram-nos que, tanto em Lisboa como em Coimbra, já desde o século XII, se criara a tradição de enviar jovens cónegos regrantes para França, porventura para Paris, frequentar as suas escolas e aí obter a licentia docendi que os habilitasse a serem mestres e pudessem ensinar em Portugal ou estar habilitados para tarefas de administração eclesial. Conhecemos alguns casos de mecenato para esses estudantes crúzios poderem, fora do país, fazer os seus estudos e o próprio rei D. Sancho I (11851211) os teria apoiado instituindo algumas bolsas com essa finalidade (GAMA

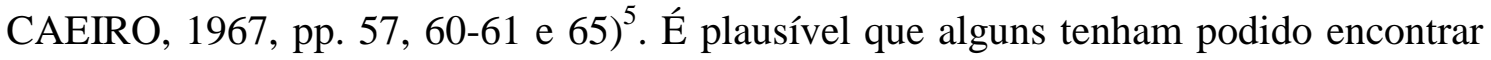
acolhimento de residência ou pousada e escola no mosteiro de S. Victor de Paris, pertencente a irmãos seus e também aberto para esse destino (CHÂTILLON, 1992, pp. 327-331).

Por outro lado, como já vimos acima, antes de meados do séculos XIII, na biblioteca do mosteiro de S. Vicente de Lisboa circulavam obras de autores e códices provenientes de França, uma das quais era o tratado da formação dos noviços, De Institutione Novitiorum, da autoria de mestre Hugo (1096-1141), fundador daquela escola parisiense e o primeiro dos autores vitorinos que a tornariam tão ilustre, naquela Centúria. Se S. Vicente de Lisboa estava ligada a Hugo de S. Victor de Paris, que dizer de Santa Cruz de Coimbra, onde eram imensas as suas obras, quase todas em cópias do século XIII e algumas do anterior?

Assim, provenientes da livraria de mão crúzia, conservados ainda hoje na Biblioteca Pública Municipal do Porto, entre a centena de códices supérstites, daquela que foi outrora a maior e mais opulenta biblioteca de Portugal, chegaram até nós, em 6 grandes volumes, alguns miscelâneos, várias das obras de Hugo de S. Victor: Anotationes elucidatoriae in threnos Ieremiae (Catálogo dos Códices da Livraria de Mão do Mosteiro de Santa Cruz de Coimbra na Biblioteca Pública Municipal do Porto, Santa Cruz, 35(1); 20; 21 (26); 16; 21 (24); 21 (25); 52; 54 e 35 (2)); In Salomonis 
ecclesisasten homiliae; De Arra Animae; De Assumptione beatae Virginis; De Sacramentis christianae fidei; De Virginitate beatae Mariae; Eulogium sponsi et sponsae; Expositio super regulam beati Augustini episcopi e Exposição sobre a Regra de S. Agostinho (Catálogo dos Códices da Livraria de Mão do Mosteiro de Santa Cruz. de Coimbra na Biblioteca Pública Municipal do Porto, 1997, pp. 204, 116, 128, 109, $245,134,256,205$ e 436).

A Biblioteca Nacional de Lisboa conserva ainda, entre os códices pertencentes outrora à livraria do mosteiro de Alcobaça, um que contém grande parte do tratado da formação dos noviços regrantes em versão medievo-portuguesa de princípios do século XV e que foi inserida entre várias passagens da Regra Beneditina e outras, anónimas. O tradutor atribuiu-a a S. Bernardo e, destacando a insistência do autor na «disciplina» a observar em vários domínios, deu-lhe por título, «Disciplina dos Monges» (BNL, Alc 200, Inventário dos Códices Alcobacenses, tomo III, Lisboa, MCMXXXII, pp. 163-165. $)^{6}$. O Inventário dos Códices Alcobacenses regista praticamente todas as obras do mestre vitorino, dando-nos a lista e descrição do conteúdo de 47 códices ainda hoje existentes na mesma biblioteca (BNL, Inventário dos Códices Alcobacenses, tomo VI (Índices), Lisboa, MCMLXXVIII, pp. 466-467.). Este autor era, assim, podemos concluir seguramente, um dos mais conhecidos e lidos em Portugal, desde o século XII.

Mas, afinal, porque se dava, em Coimbra, em Lisboa e em Alcobaça, tanta importância às suas obras? Quem era Hugo de S. Victor? Que valor especial tinha o tratado sobre a formação dos noviços que o tornasse tão atractivo?

\section{HUGO DE S. VICTOR}

A vida de Hugo de S. Victor de Paris (1096-1141) é mal conhecida. Originário, provavelmente, do Saxe e de família nobre, cedo saiu da sua terra natal, de que se lembrava com nostalgia «Ego a puero exulavi, et scio quo maerore» (S. VICTOR, 1991, p. 155) ${ }^{7}$. Era sobrinho de um outro Hugo, arcediago da catedral de Halberstadt, e terá nascido por volta de 1090-1100. Feitos os primeiros estudos, professou nos cónegos regrantes do mosteiro de Hamersleben, recentemente fundado. Protegido pelo tio, mecenas da nova instituição das margens do Sena, Hugo chegou a Paris ainda jovem, ingressando na abadia de S. Victor, por volta de 1115-1117, poucos anos após a sua fundação, vindo aí a tornar-se Mestre, antes de 1127. Seria o primeiro e fundador da escola de uma série de ilustres 'mestres victorinos' que, a par das escolas seculares, no século seguinte, dariam origem à universidade. 
Hugo iria consagrar o essencial da sua curta existência de uns quarenta e cinco anos, ao ensino, à escrita e à oração, tanto litúrgica como pessoal. Como mestre e como autor, cedo adquiriu prestígio que lhe atrairia discípulos de tudo o Ocidente cristão, em especial da França, Inglaterra (Ricardo e André) e Itália (Pedro Lombardo, recomendado pelo ilustre $\mathrm{S}$. Bernardo de Claraval).

Como situar Hugo entre os pensadores e mestres do seu tempo?

Pertencente à brilhante geração dos grandes espíritos criadores de instrumentos novos de saber (seguidamente aperfeiçoados pelos seus sucessores), na primeira metade do século XII, como Pedro Abelardo (+1142), Guilherme de Conches (+1154), Thierry de Chartres (+1155), Gilberto de la Porrée, S. Bernardo de Claraval (+1153) ou o mestre Pedro Lombardo, das Sentenças (+ 1160), a inserção cultural de Hugo fez-se na charneira de dois mundos, o dos Antiqui e dos Moderni, isto é, entre uma Idade Média que acabava e outra que se abria, carregada de promessas, inovações, mudanças e debates ${ }^{8}$.

A principal das suas obras educativas, escolares, a que, por volta de 1125 , deu o significativo título grego de Didascalicon, está já marcada pelo élan da modernidade, da jovial confiança no poder da inteligência alargada até ao extremo, de amplo programa, que ele sintetizou na afirmação: «Aprende tudo, e verás que nada é supérfluo» (S. VICTOR, 1991, p. 212).

Hugo também é moderno pelo cuidado que mostra em se informar nas melhores e mais seguras fontes do saber e no acolhimento das aquisições dos seus contemporâneos, tendo em conta a diversidade das suas experiências e divergências dos seus conhecimentos. É moderno na observação desse mundo em mudança que o rodeava e na preocupação de organizar e enquadrar, em princípios de inteligibilidade, as aquisições do seu tempo, alargando desta forma o quadro dos saberes tradicionais e incluindo muitos outros, ignorados ou desprezados. É moderno pelas autoridades clássicas que invoca e que o situavam assim no movimento novo do «renascimento do século XII» ${ }^{9}$

Decerto, em tudo isto beneficiou da circunstância de membro da comunidade fundada por Guilherme de Champeaux, em 1108, às portas da cidade e que, desde o início da segunda década do século, como refere Georges Duby, já se transformara no «grande atelier de soluções pastorais, portanto pedagógicas - uma escola de mestres, (...) lugar ideal para redigiu o seu Didascalicon, magnífico projecto de renovação de um sistema de ensino» (DUBY, 1982, pp. 267-268). 
Por outro lado, porém, todo o pensamento de Hugo se organiza em volta de duas ideias e preocupações augustinianas, vindas da Antiguidade Tardia: a da unidade essencial do saber e a de que o homem, depois da queda original dividido, pode ainda, refazendo as suas forças, pelo trabalho da razão e pela aquisição de conhecimentos, proceder à obra da sua 'restauração' («opus restaurationis»), enquanto natureza humana de original semelhança divina.

A estas ideias dá Hugo uma tonalidade muito própria, encontrando um método novo e uma perspectiva optimista (nisto se afastando do hiponense) que lhe permitem estruturar a sua visão enciclopédica das coisas. Daí a importância do sensível e do quotidiano; e a curiosidade ter para ele um valor positivo, por ver nela a forma de reconduzir a atenção e a acção do homem para a inteligência da Natureza, isto é, para a obra do Criador.

Desta posição decorre o lugar dado por Hugo às actividades técnicas e mecânicas, importantes não apenas porque asseguram ao homem a realização das suas necessidades básicas de existência; mas, também porque são a forma, acessível a todos, de redescobrir a dignidade da natureza humana pelo trabalho das mãos e do espírito, fazendo dele colaborador de Deus e recuperando assim aquela semelhança perdida entre criatura e Criador.

Homem na charneira de dois tempos, Hugo é, por outro lado, ainda devedor da tradição pela impossibilidade de poder, durante a sua curta vida, dispor daquele corpus aristotélico, mediado pelo pensamento árabe, e só disponível para dar frutos no Ocidente cristão na segunda metade do século XII, graças ao trabalho das grandes traduções feitas sobretudo na Península Ibérica. Por razões de tempo, as suas fontes são, em grande medida, ainda tradicionais: além de Agostinho, Macróbio, Marciano Capela, Boécio, Cassiodoro e Isidoro de Sevilha (o mais citado de todos os autores no Didascalicon).

A sua inclusão e elogio de saberes novos, organizados em sete artes mecânicas (fabricação de têxteis, produção de armas, viagens de navegação, trabalhos agrícolas, actividades de caça, teoria e exercício da medicina e acções lúdicas e desportivas - a scientia theatrica) (S. VICTOR, 2001, p. 120), a par das sete artes liberais, fazem-se no quadro dos auxiliares da compreensão das Escrituras Sagradas, à semelhança do que S. Agostinho propusera no seu manual De Doctrina Christiana, no século V. É um voltar-se para o passado, mitificado, que importava restaurar, como meio de garantir o futuro, mais do que uma análise racional do mundo empírico e 
material reabilitado. O destaque dado ao elogio dos mercadores, o prestígio dos agricultores, a distinção pedreiros e dos arquitectos, a ousadia dos navegantes, o apelo aos novos estudantes, não são ainda um estudo crítico de processos e movimentos. São formas de ler a história e sinais de tomada de consciência da sua evolução, especialmente no mundo urbano que um adágio um pouco posterior traduziria na afirmação que sintetizava aquela atmosfera: «o ar da cidade torna o homem livre»!

Mesmo a partir da leitura destas suas duas obras tão modernas, Hugo de S. Victor mostra ser ainda um homem do 'universo monástico', tanto pelo espírito voltado para a vida espiritual como pela sua reflexão feita a partir de experiências externas e internas que faz desembocar na Sabedoria, e sempre na perspectiva de uma antropologia de intenção mística, bem distante das preocupações de luta verbal ou polémica a que a os dialécticos, a dialéctica e a disputatio, nas escolas ao lado, conduziam. Por isso, mestre Hugo não mostrou grande simpatia pelo coetâneo mestre Pedro Abelardo, não poupando ironias e críticas (veladas) a métodos e comportamentos onde, a seu ver, predominava a desmesura das palavras e dos gestos e os objectivos se afastavam da prossecução da Sabedoria. No entanto, a hostilidade não anulava muitos pontos que ambos tinham em comum, enquanto actores da grande viragem cultural e de fomentadores do «novo despertar evangélico» (CHÂTILLON, 1992, pp. 34-39) reformador.

Por tudo isto, Hugo é bem, na primeira metade do século XII, o representante típico do cónego regrante, acusado de ser espécime eclesiástica híbrida que, por entre ambiguidades procurava construir a sua identidade, sui iuris, bem definida, entre o modelo monástico e o modelo escolástico. Decidindo distanciar-se do primeiro, por prática de regra diferente (a Regra de S. Agostinho é uma regra de cidade imperial) e outros objectivos, a sua schola situava-se às portas da cidade para lhe denunciar as contradições «quoniam vidi contradictionem in civitate ...» ${ }^{10}$ e lhe propor formas novas de educação e comportamento «aedificare verbo et exemplo» (BYNUM, 1973), precisando para isso de inventar adequados instrumentos de diálogo e influência eficaz, que haveriam de passar pelo ensino e doutrinação renovados, pela amplidão de vistas pastorais, pela ousadia de contactos fermentadores. Um tratado anónimo que, por volta de 1120, circulava, não lhes poupava elogios:

os cónegos regrantes vivem na cidade: como Cristo e os discípulos estão às portas para entrar em Jerusalém e aí celebrar a última Páscoa; estes clérigos vieram viver na cidade para mostrar aos homens que nela vivem, a via da salvação» (Liber de diversis ordinibus et professionibus quae sunt in Ecclesia, (PL 213, cols. 807-850). 
Era elogio e desafio: eduquem-na se a querem salvar!

Em Hugo nós vemos essa tensão criada entre aqueles ideais atrevidos e sedutores mas também a recusa aberta da dialéctica, e dos seus arriscados métodos guerreiros de disputatio, permanecendo num ideal irrealizável e que, só no século seguinte, com o aparecimento dos frades, haveria de encontrar alguma concretização. $\mathrm{O}$ modelo canonical de intervenção na cidade ficou indefinido, foi ultrapassado e aos seus defensores só restaram dois caminhos divergentes: algumas comunidades voltariam a dissolver-se nos cabidos das catedrais a que, inicialmente, se propunham como alternativa; outras, a maioria, detentora já de rico património material e intelectual, reorganizam-se, monaquizando-se, mas perdendo também aquele espírito distintivo que inicialmente as animava, de reformar os clérigos para melhor reformar o maior número dos homens e as suas comunidades mais dinâmicas e promissoras onde tudo se joga as cidades. Julgo podermos ver aqui a raiz da hostilidade de Pedro Abelardo contra os Regrantes que, mais do que uma incompreensão da sua parte e uma motivação

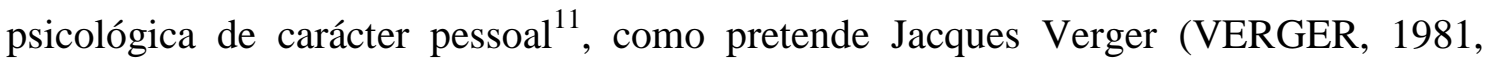
p.129), me parece ser também a aguda consciência que o dialéctico teve das suas contradições e limites (Petrus Abelardus, «Epistola contra quemdam canonicum regularem qui monasticum ordinem deprimebat et suum illi anteferebat», $P L 178$, cols.). O evoluir das duas canónicas portuguesas e um dos destinos que em Portugal foi dado ao tratado vitorino de formar noviços é a prova clara de quanto acabamos de observar: os dois mosteiros, de Lisboa e Coimbra, cedo foram ultrapassados mesmo pelo dinamismo cultural e pastoral dos mosteiros cistercienses, e em Alcobaça, o De Institutione Novitiorum foi vertido em linguagem vernácula e adaptado para servir a monges de Cister, passando a circular, como vimos, como parte integrante de uma obra, doravante atribuindo-o a S. Bernardo de Claraval (BNP, Alc 200, fls. 148-180, A qui se começa oliuro que chamõ deçeplina ..., (CARTER, 1940, p.359-395; MARTINS, 1961, p.633-644)

Foi assim, neste contexto de tensão, mas ainda numa época de esperança, que no séc. XII, nasceu a obra indicada no nosso manuscrito do séc. XIII do mosteiro de S. Vicente de Fora e que se destinava, em Lisboa, como em Coimbra, a formar as gerações regrantes portuguesas, De Institutione Novitiorum. Hugo redigira-o em Paris, por volta de 1130, a par da obra mais propriamente escolar do Didascalicon, de studio legendi, de 1125. Ambas se completam como duas asas articuladas de um díptico que 
deve ser visto em conjunto ${ }^{12}$. Nesta última, cronologicamente anterior, Hugo traça as linhas mestras de um novo programa escolar e indica o método dessa nova 'arte de ler'. Pretende mais persuadir do que convencer; recupera para os métodos de aprendizagem a ludicidade dos processos; o diálogo nos debates, visa, objectivamente, restaurar o homem integral pela obtenção da Sabedoria, no final do caminho da ciência, da disciplina e da bondade.

Como ciência, cujo objectivo é formar para uma vida recta, é, assim, um guia do que se deve ler (estudar, aprender, saber), em que ordem e de que maneira. É lectio pessoal, mas é também programa de estudos de uma escola. Não o encontramos documentado em nenhuma das listas de manuscritos das duas canónicas portuguesas! Mas não faltava em Alcobaça, numa cópia que ainda hoje se conserva (BNL, Alc LXXIX (155), Inventário dos Códices Alcobacenses, tomo II, Lisboa, MCMXXX, pp.126-126 e tomo VI, Lisboa, MCMLXXVIII, p. 466).

A originalidade do Didascalicon, em seis livros, está em afirmar que há igual dignidade entre os saberes ligados à vida material (artes mecânicas) e as disciplinas do trivium e do quadrivium (artes liberais), porque o laço da sua unidade permite formar com todas elas um conjunto sistémico e submetê-las a uma nova classificação: todas são partes de uma filosofia que se enquadra em quatro domínios: teórica, prática, mecânica e lógica.

Os seus últimos livros guiam, directamente, o estudante a ler as Sagradas Escrituras. Para esta lectio divina Hugo precisa as regras, sendo a história, que é o seu primeiro sentido, a sua primeira norma e disciplina. Só por ela se chegará às outras duas, a alegoria e a tropologia. Quando se pratica, a própria lectio divina produz frutos: instrui com a verdade e, pela contemplação, incita ao amor, o que quer dizer, reunifica o homem, produz-se, então, nele a tal restauração a integralidade da imagem divina perdida e de que andava carente.

Ficava assim definido o programa de estudos e a marca distintiva do fundador da escola vitorina, a imprimir na formação geral e básica dos estudantes (internos e externos) que acorriam à canónica de Paris: lectio meditatio, contemplatio, em grande parte afastado de um ideário divergente que, lado a lado, na mesma cidade, se ensinava no fervilhar das suas escolas seculares: lectio, quaestio, disputatio que mestre Hugo não deixa sem reparo através de subtis ironias: 'atrai muitos estudantes mas faz poucos sábios' (S. VICTOR, 2001, p. 139)! Divergente também, daquele outro 
itinerário que, no final da centúria e na seguinte, outros ensinarão: lectio, disputatio, praedicatio.

Não se pense porém, que se tratava de um programa abstracto ou um puro ideal místico. O mestre adianta como quer a sua escola, que já definira com o lema «Aprende tudo e verás que nada é supérfluo» (S. VICTOR, 2001, p. 239). No diálogo visual, a que subjaz uma verdadeira cartografia das técnicas, entre Indalécio e Díndimo, o primeiro elogia-lhe a composição e as suas virtualidades:

- Vejo uma grande turma de alunos. São muitos e noto que são de diferentes idades: crianças, adolescentes, jovens e idosos. Também as matérias de estudo são variadas. Uns treinam para habituar a sua língua, ainda inculta e bárbara, a pronunciar novas letras ou a articular palavras desconhecidas. Outros aplicam-se a conhecer, ouvindo primeiro, as declinações das palavras, as suas composições e derivações; aproximando-as, em seguida, umas das outras e, repetindo-as muitas vezes, esforçam-se por gravá-las bem na memória.

Com um estilete alguns escrevem em tabletes de cera; outros, com a mão já experimentada, traçam no pergaminho letras de diversas espécies e a diferentes cores. Outros ainda, mediante um esforço mais agudo mas, cheios de entusiasmo, debatem em conjunto matérias, ao que parece, importantes e, por certos artifícios de linguagem esforçam-se por se enganar uns aos outros.

Vejo também alguns que utilizam o ábaco. Outros, batendo uma corda tensa num cavalete de madeira, extraem dela melodias de sons variados. Há-os que comentam figuras e discutem diversos tipos de medidas, enquanto alguns descrevem claramente, por meios de certos instrumentos, o curso e a posição dos astros por entre os movimentos do céu.

Há alguns que se ocupam com a natureza das plantas, com a complexidades dos homens e outros, com a multiplicidade das virtudes das coisas.

Em tudo isto se vê como são variadas as maneiras de aprender, embora a vontade de progredir seja característica de todos. (...).

Mais atento ao fim último a alcançar do que à multiplicidade dos saberes escolares e dos métodos, Díndimo replica ao companheiro:

- Muito bem! Aí estão todos esses trabalhos, não da sabedoria, mas da loucura dos
homens pela qual os imprudentes e insensatos, através de um esfoço, vão e fútil, se
inquietam em descobrir a natureza das coisas, ao mesmo tempo que ignoram o
próprio criador, artesão de todas essas naturezas. Negligenciam pôr-se a pesquisar,
como se alguém pudesse, sem Deus, encontrar a verdade e chegar à felicidade. É
que, sem esta condição, todos esses estudos são infrutíferos e, digamos mesmo,
perniciosos: não só não iluminam as almas para que conheçam a verdade, como as
cegam totalmente, a fim de que nem a possam sequer vislumbrar. (...) Exilados de
si próprios, esquecem-se de que estão apenas a caminhar e não procuram mais a
pátria, seu destino» (S. VICTOR, Hugo de, De Vanitate Mundi, PL 176, cols. 709
C s.).

O programa de estudos vitorino é, assim, já, directório e terapia espiritual: a aquisição do verdadeiro saber precisa de ser acompanhada pela renúncia de qualquer tipo de poder! ${ }^{13}$ Tal programa seria retomado e aprofundado pelo mesmo Mestre, 
poucos anos depois, para aqueles que, como ele, se destinavam às fileiras regrantes no breve tratado De Institutione Novitiorum. Viria a ser uma das suas obras de maior sucesso na Idade Média: dela subsistem 172 manuscritos conhecidos (contra 125 do Didascalicon) mas, foi também muito citada por outros autores, incluída, em parte ou na totalidade, em outras obras, traduzida em vernáculo, adaptada, reelaborada. São vinte e um capítulos, antecedidos de um prólogo em que enuncia o seu objectivo: ensinar aos noviços «a via»; «o caminho para a felicidade eterna, através da ciência, da disciplina e da bondade» (S. VICTOR, 1997, pp. 18-20).

No trabalho de formação dos futuros educadores da cidade - «vós que abandonastes os vossos bens e já nada vos prende»(S. VICTOR, 1997, p. 21) adquiridos os fundamentos básicos de um saber renovado, Hugo dirige-se à pequena elite regrante a quem propõe, com a condição de adquirir «a ciência», isto é «o verdadeiro discernimento» (c. I-IX) ${ }^{14}$ e «a disciplina» (c. X-XXI) (S. VICTOR, 1997, pp. 20-22), num grau mais elevado e como etapa prévia, para alcançar a via ética, a via do humanismo antropológico e cívico ${ }^{15}$, em que inclui comportamentos e atitudes a aprender e que ele organiza em quatro grandes domínios: - o do vestir e do calçar; - o dos gestos e das atitudes; - o da palavra e do silêncio; - o das boas maneiras à mesa.

Como indicou no prólogo, os dois conceitos-chave do seu sistema educativo são a «ciência» e a «disciplina». Já vimos como entendia a ciência. Vejamos o que entende por «disciplina».

No seu Didascalicon (S. VICTOR, 2001, p. 155), dirigindo-se a todos os estudantes, recuperando a definição que a tradição ligava a Marciano Capela e Boécio, a disciplina era um saber, uma matéria de ensino, complementar da «arte» (SCHMITT, 1990, p. 175).

Nesta outra obra, destinada à pequena elite já avançada dos que «haviam deixado a vã conversação do século e caminhavam no processo de conversão religiosa», como refere no prólogo, a disciplina é entendida como «arte de viver ('conversatio') boa e honesta para quem não fazer o mal é pouco, mas procura fazer o bem e em tudo aparecer irrepreensível». É ainda, num terceiro sentido, o «movimento harmonioso de todos os membros e a boa inclinação para todos os hábitos e todas as acções» ou o esforço para o conseguir. Neste último caso, a disciplina é uma prática de mortificação e mesmo instrumento punitivo (vara, régua ou chicote) e, por isso, meio penitencial - sentido que se tornaria mais vulgar e específico dos meios monásticos. 
Para análise de cada um dos quatro registos comportamentais acima referidos, Hugo parte da ideia-chave de que há uma relação íntima entre $o$ exterior $e$ o interior (corpo-alma), o fora e o dentro. Utiliza sempre o mesmo método que articula em quatro tempos: primeiro, enumera as circunstâncias, deixando aberta a porta das suas potencialidades; depois, procura os preceitos colhidos nas Escrituras Sagradas; a seguir, faz a caricatura dos comportamentos contemporâneos que ele, finamente, observou, e de que dá uma viva descrição, servindo-se do riso, da ironia e da sátira para o seu descrédito e combate; finalmente, por aproximação dos opostos, num quadro amplo e aberto, edita normas positivas e concretas para gravar na memória e, doravante, seguir. Fica assim traçado um quadro, que se mostraria especialmente eficaz na transmissão de códigos de comportamento.

DISCIPLINA NO VESTIR:

Quando mestre Hugo ensina a forma de trajar de um noviço vitorino, sabe que a Regra de S. Agostinho não é uma regra monástica, de retracção, mas antes de exposição de si, publicamente aos outros (FALQUE, 2011, p. 390). Além do ideal de perfeição, o regrante professa os deveres de apostolado e de ensino. Em Paris, como em Lisboa ou em Coimbra, vive num mosteiro aberto e com uma biblioteca aberta à cidade, expõe-se, pois, está frequentemente na cena pública da escola ou da colaboração na chancelaria régia (ROMAGNOLI, 1991, p. 43). Não deve tentar agradar pela maneira de vestir mas, «verbo et exemplo» («Non sit notabilis habitus vester; nec affectetis vestibus placere, sed moribus», Praeceptum, in PL, 32, col. 1380), pois aquela traduz o que lhe vai na alma.

No domínio do vestuário é a forma de vestir que gera ou não a harmonia, mais do que a espécie dos tecidos, a sua cor ou a própria veste. Não que entre os vitorinos houvesse moda mas, os irmãos podiam distinguir-se uns dos outros pelo modo como se apresentavam vestidos e calçados (JOCQUÉ, 1991, pp. 53-95) ${ }^{16}$.

Sendo assim, em S. Victor, no domínio do vestuário, bem podemos dizer que «o hábito faz o monge»! Não no sentido de que basta vesti-lo para se ser bom religioso, mas porque a escolha do vestuário exterior diz como vai o interior.

A disciplina neste domínio deve guardar-se, lê-se na versão alcobacense, «no preço, na brandura e na collor: que não seja o pano de valor, nem mui sotil, nem de fremosas vestiduras» (CARTER, 1940, LINHAS 578-580).

É com humor e refinada sátira que Hugo observa o que diz ver à sua volta: 
Há alguns tolos que, desejando agradar a outros tolos, se adornam de muitos artifícios, Alguns, por tolice ainda maior, vestem de maneira ridícula e outros, para se exibirem fazem gala dos seus trajes, o mais que podem. Há-os que coleccionam túnicas de largas mangas e tufadas em escada, outros entrouxam-se em franjas, fitas e dobras de luxo. (...)

Alguns agitam ao vento as pregas do seu hábito, mostrando a ligeireza do seu espírito pela febrilidade da sua postura. Outros, ao caminhar varrem o solo por onde passam mas apagam logo os traços da sua passagem com as franjas e caudas que arrastam pelo chão. São semelhantes a raposas que ostentam longas caudas» (S. VICTOR, 1997, pp. 51-53).

Já cansado de enumerar exemplos o mestre conclui: «não tenho gosto algum em continuar com estas frioleiras vaidosas pelas quais tolos e insensatos parecem ter aprendido com as mulheres, ou melhor, com as prostitutas, as suas práticas e, com tanta infâmia como parvoíce, quase mudam de sexo, ao mesmo tempo que de hábito» (S. VICTOR, 1997, p. 53).

Assim,

«os que amam a vida religiosa sabem desprezar os bens terrestres e não prestam culto supersticiosa ao corpo, sabendo que vai morrer. Para ele, preferem os enfeites dos bons costumes ao fausto e luxo do vestuário; preferem as roupas vis às preciosas; as grosseiras às delicadas; as rudes às efeminadas; as escuras às garridas; as que não têm acabamentos às requintadas.

E conclui apelando à disciplina: «Eu sei que os espíritos duros e rebeldes não se afastam facilmente da via do erro inveterado, enquanto não forem refreados por rédeas mais mordentes».

Em Portugal, os Regrantes faziam-se eco destas críticas recorrentes mas sempre actuais para cada geração de novos adventícios. Invocando a autoridade de Hugo de S. Victor e do seu De Institutione Novitiorum, um capítulo geral reunido no Porto em 1230, e de que possuímos as actas, escalpeliza veementemente, de certo com alguns tópicos de retórica, aqueles que usam tabardos, escapulários e pálios de peles preciosas ou vestem caras garnachas de penas que abrem à frente; outros exibem sapatos castanhos de tecidos raros e longas pontas arrebitadas, ou usam finos pentes de marfim para altear as marrafas na fronte e as tornear com pendentes nas orelhas (BPMP, Santa Cruz 93, fls. 76-81, Gemma Corone Claustralium et Speculum Prelatorum Ordinis Sancti Augustini) ${ }^{17}$.

\section{DISCIPLINA NO GESTO}

Definindo o gesto como «uma medida e postura dos membros do corpo adaptados a todo o modo de acção ou comportamento» (S. VICTOR, 1997, pp. 58$59)^{18}$, Hugo analisa-o, distinguindo a partir de seis circunstâncias. Situa-o, 
seguidamente, no quadro das clássicas metáforas: a cosmológica, do corpo humano como um microcosmo e a política, onde o corpo é visto como uma res-publica, assentando tais imagens na ideia bíblica de que o corpo é intérprete do seu espírito: a harmonia ou agitação do primeiro, traduzem e reflectem a saúde moral ou a doença do segundo, sendo porém que, pelo controle de um, se consegue o domínio do outro:

«Pelo semblante se conhece o homem; pelo aspecto do rosto, o sábio. A maneira como um homem se veste ou a sua forma de andar, revelam aquilo que ele $e^{1}{ }^{19}$. «Os movimentos desordenados são sinal de um corpo corrompido e de um espírito dissoluto (...). O homem depravado e iníquo põe a boca torta, pisca o olho, arrasta os pés, estala os dedos» ${ }^{20}$ !

Nesta grafologia comportamental a versão alcobacense acrescenta portuguêsmente: «Há-os que cerram um olho e abrem o outro, e quando se soam, torcem e estiram os narizes e fazem-nos ringer!» (CARTER, 1940, linha 1080).

E continua o texto latino:

«De facto, alguns não sabem escutar o que se lhes diz se não de boca aberta, escancarando, às palavras do orador, o antro bucal, como se o sentido do discurso devesse correr por ali abaixo até ao coração! Pior ainda, outros, quando escutam, põem a língua de fora, como cães sedentos e cansados, e quando agem, mordem os lábios, aparentando o tormento de quem faz girar a mó de um moinho»!

A dimensão visual (SICARD, 1996, p. 101) e mesmo estética da sua reflexão hermenêutica dos tipos sociais de indivíduos fá-lo traçar quadros cuja dimensão sensível aponta para a monstruosidade gestual:

«O homem que caminha, remando com os braços é uma espécie de monstro duplo que, enquanto anda sobre a terra com os pés, parece voar no ar com os braços. Tal homem confunde, assim, os três elementos: a água (onde parece navegar), a terra (que pisa com os pés) e o ar (que agita com os braços). Imita a ficção do pintor, que segundo o poeta Horácio, junta um busto de mulher a uma cauda de peixe, para representar uma sereia!» (S. VICTOR, 1997, p. 71).

Tal como S. Bernardo de Claraval reprovava a Cluny a representação de centauros e quimeras nos capitéis e frescos dos seus claustros (CLARAVAL, 1997, p. 67), Hugo desconfia deste hibridismo e desta mesclança, que cria monstros, porque atenta contra a ordem da criação; mas não ignora, por outro lado, como os monstros 
podem ser sinais cuja reflexão nos mostra como da transgressão se tira ensinamento que serve para afirmação da norma.

É neste sentido que Hugo afirma:

Todos estes se esquecem de que o corpo humano é uma 'república' e que nela cada membro tem a sua própria função. Por isso, quando um membro reivindica, atabalhoadamente, a função de outro, que faz ele se não perturbar a harmonia do conjunto?

E, educador atento, continua:

Assim, a primeira observação a fazer na disciplina do gesto é que cada membro se atenha à sua própria função e não perturbe as dos outros. Os olhos vêem, os ouvidos ouvem; as narinas cheiram; a boca fala; as mãos trabalham; os pés caminham (...).

A segunda observação é que cada membro faça o que deve fazer, na maneira e na medida necessárias, nem de mais nem de menos, nunca excedendo os limites da moderação e a forma da probidade: rir, sem mostrar os dentes; ver, sem arregalar os olhos; falar sem agitar as mãos nem apontar com os dedos ou morder os lábios, menear a cabeça ou arquear as sobrancelhas; andar, sem gingar as ancas nem bambolear os braços ou rebolar os ombros; sentar-se, sem agitar as pernas, cruzando e descruzando os pés nem se apoiar nos cotovelos; deitar-se, sem esparramar o corpo, dengosamente!

Ironicamente, mestre Hugo acautela-se a si mesmo: «Com receio de nos entusiasmarmos nestas críticas e resvalarmos mais para a sátira do que para a educação, não esqueçamos nós mesmos a moderação!» (, p. 71). Em tudo inculca a justa medida, o meio termo: «Desta forma, o gesto do homem deve ser gracioso, sem moleza; calmo sem relaxamento; grave sem preguiça; firme sem agitação; decidido sem atrevimento, severo sem perturbação».

Em casos extremos, Hugo não desdenha aconselhar os castigos corporais, como forma correctiva e de adquirir bons costumes:

Eu bem sei como é difícil disciplinar um coração empedernido pela malícia ou dobrar um corpo rebelde ao respeito da probidade. Mas, quando o ferro é duro, dificilmente ganha forma pelo bater do martelo simples; é preciso aplicar-lhe um fogo mais intenso e uma martelada mais vigorosa.

Atento às circunstâncias, Hugo sabe que a disciplina, porém, não é igual para todos. Como veremos mais adiante, ao falar das boas maneiras à mesa, tal como nem todos precisam de comer a mesma quantidade de alimentos, também as correcções pedagógicas devem ser adequadas a cada indivíduo, pelo que é necessário prestar-lhe atenção, na sua singularidade.

Hugo, como conclui Jean-Claude Schmitt (1990, p. 194), em todo este processo, ajuda assim, no princípio do século XII, a aprofundar a noção de «indivíduo», 
na linha de Pedro Abelardo, das circunstâncias e das intenções pessoais, que tanto ajudariam no esclarecimento em curso da moral penitencial.

\section{DISCIPLINA NA PALAVRA:}

Este aspecto ligava-se com o outro domínio de aplicação da disciplina que Hugo elegera e que era preocupação maior da ética medieval, numa sociedade ainda dominada pela oralidade: o bom e mau uso da palavra, apressando-se a determinar as cinco circunstâncias da sua análise: o que dizer, a quem, onde, quando e como. A principal regra de base que o vitorino queria inculcar aos seus noviços é que nunca se deve esbanjar uma palavra e devem apenas ser pronunciadas as úteis e as necessárias (CASAGRANDE \& VECCHIO, 2007, pp. 69-73) ${ }^{21}$.

No que se deve dizer, Hugo seleciona o conteúdo do discurso: devem evitarse as palavras ociosas, isto é, as inúteis, as desonestas e as nocivas. Três tipos interditos que se reconhecem pela qualidade das coisas de que se fala e das pessoas que falam ou escutam e, ainda, de quem se fala! A circunstância de a quem se fala mostra conteúdos e interlocutores possíveis: fala-se de liberalidade aos avarentos e de firmeza aos timoratos. Por seu lado, o ouvinte é sempre um mestre a interrogar ou um discípulo a instruir.

A hierarquia das palavras corresponde à hierarquia dos lugares: há lugares onde o silêncio é perpétuo e outros onde se pode falar desde coisas mais espirituais e sagradas até às mais materiais e profanas ${ }^{22}$. É esta hierarquia que define e estrutura os lugares. Note-se, porém: em nenhum lugar se pode falar de coisas vãs e supérfluas!

A disciplina do quando refere a importância do silêncio antes de falar, em quatro circunstâncias: quando outro está a falar; quando o ouvinte não está preparado; quando não sabemos o que dizer; e quando o interlocutor ou nos é superior e inspira respeito, ou nos é muito inferior e seria perder tempo tentar corrigi-lo com palavras!

Como falar diz respeito aos gestos do locutor, ao sentido e conteúdo do discurso. Palavras úteis permitem gestos moderados para agradar; de conteúdo verdadeiro e tom suave, para não assustar, quando as verdades são duras de ouvir.

Acautelando o que usa palavras de correcção de possível contágio rectroactivo, diz a versão medieva em português: «O que repreende o que é mau, acrescenta maleza para si; por isso, não queiras tu repreender ao escarnidor, logo non te queira mal». E acrescentando o princípio do antídoto da medicina clássica: «[deve] poer-se sempre a mezinha por contrairo: assim, aos gargantões [aconselha] abstinência, 
aos sofrudos a mansidão de paciência, aos negrigentes a justiça, aos cruéis a perdoança, aos atrevidos a vergonça e aos rebatados o assossego»(CARTER, 1940, 1. 765; 780).

Vemos como para Hugo o esquema da análise das circunstâncias se revela o meio mais adequado para ditar normas ou proibições que os séculos seguintes divulgarão já transformadas em aforismos: 'Que ninguém fale do que não sabe!' 'Que se guarde silêncio e concentração antes de falar!', 'Quando um fala ..., etc.

Desta forma, podemos concluir com Carla Casagrande e Silvana Vecchio (2007, p 72), cuja análise , nesta matéria, temos vindo a seguir:

Os princípios e valores que presidem à disciplina da palavra marcarão profundamente toda a educação e cultura medievais:

- Superioridade da palavra sagrada sob todas as suas formas: palavra de Deus, palavra sobre Deus, palavra a Deus.

- Vontade de reduzir todas as formas de comunicação à comunicação modelo, onde tem mais sentido o diálogo: a comunicação entre mestre e discípulo.

- Persistência quase obsessiva de afastar a palavra vã e de encontrar a palavra útil e eficaz.

- Certeza de que a posse da palavra justifica uma hierarquia social e religiosa que, por sua vez, fundamenta a hierarquia dos modos de transmitir a própria palavra

É notável e foi decisivo o contributo de Hugo de S. Victor em ter unificado na modalidade articulada e sistemática da lista das circunstâncias todo este património de valores e de normas, pondo o problema da palavra e abordando-o na sua totalidade.

Se a proposta era excelente para os cónegos regrantes, que associavam o ideal de perfeição religiosa com os deveres do apostolado pastoral e escolar, não se mostraria menos adequada, um século depois, para as Ordens Mendicantes que se debateram com problemas semelhantes, ao impulsionar a prática da pregação. Mas, a proposta vitorina mostrar-se-ia também adequada às Ordens religiosas mais tradicionais de cenobitas e mesmo de ermitas: a cópia do texto vitorino circulava em vários manuscritos das livrarias desde o ermitério de Grandmont, em França, ao mosteiro cisterciense de Alcobaça, em Portugal!

Porquê tão grande atracção e maleabilidade do texto?

A força da disciplina de Hugo reside precisamente na sua generalidade e na capacidade abstracta de, a partir de condições especiais, poder ser aplicada, sucessivamente a diferentes meios e com várias modificações. A força está na lista das 
circunstâncias, em si um esquema vazio, mas feito para poder encher-se, da maneira como ele o utilizou e ensinou a utilizar.

Por outro lado, esta rigorosa disciplina da palavra, segundo o texto de Hugo, é já uma etapa avançada num processo de conversão religiosa: destina-se àqueles que já passaram as primeiras etapas, mas é também parte de uma disciplina de exterioridade que, por definição se ocupa dos modos do parecer.

Ora, são sobretudo aqueles que exercem funções públicas, que estão sempre em cena social que devem parecer exemplares, irrepreensíveis e harmoniosos nos gestos, na forma de vestir, de falar e de comer.

Ao longo da história as circunstâncias qualificaram as palavras dos sábios, retores, pastores religiosos. No texto de Hugo elas pretendem qualificar personagens que não são diferentes daqueles, nem pela posição nem pela função, ensinando, reprovando, consolando - os novos educadores da cidade !

Por tudo isto, concluímos com as autoras citadas:

Estas páginas de Hugo marcam uma passagem fundamental na história das circunstâncias. Grande parte da tradição anterior para ela conflui e a tradição do futuro já aqui se encontra prefigurada: o momento em que as circunstâncias revelam toda a sua potencialidade é igualmente aquele em que as fronteiras no interior das quais essa potencialidade poderá exercer-se, ressaltam nitidamente» (CASAGRANDE; VECCHIO, 2007, p. 73).

\section{DISCIPLINA À MESA}

Quanto à mesa, lugar de sociabilidade por excelência, à disciplina Hugo precisa dois aspectos: na atitude e na comida, mais uma vez esmiuçando as circunstâncias de cada um:

- Na atitude de comer, três maneiras: em silêncio (dados os perigos da língua e da boca que come, bebe e, ao mesmo tempo, quer falar), de olhar contido (para 'não ter mais olhos do que barriga'), com domínio de si em todos os seus membros.

- Na comida, outras três: o que comer, em que quantidade e com que maneiras ${ }^{23}$.

Invocando o vício da glutonaria (CASAGRANDE; VECCHIO, 2003, pp. 193-228) e as maneiras lamentáveis usadas por alguns dos seus confrades, Hugo traçanos, acerca da forma de comer, uma das suas mais brilhantes caricaturas:

Alguns, uma vez sentados à mesa para comer, dão logo sinal da anarquia que the vai na alma pela agitação e desordem febril de que dão sinais: abanam a cabeça, alargam os braços, levantam as mãos, como quem se prepara para engolir todo o festim, por si só e de um trago!

Bufam, arregalam os olhos, suspiram de angústia, de tal forma que parece procurarem meios de alargar o acesso que conduz ao seu ventre voraz, como se a 
estreiteza da goela fosse insuficiente para fornecer ao estômago esfomeado a abundância por que anseiam!

Do lugar onde estão sentados conseguem, com os olhos e as mãos, controlar tudo, perto e longe.

A versão alcobacense tem sabor mais pitoresco:

Andam com os olhos catando e vendo o que os outros comem, e com as mãos apalpando as cousas que estão em a távola, tão bem as que estão longe como as que estão acerca; esmigalham muito pam, enchem as taças e os vasos de vinho em tanto que, às vezes, o vertem por a mesa e isso mesmo as escudelas de caldo Ao mesmo tempo que esmigalham o pão, enchem os copos de vinho até verter, puxam para si as travessas e, tal como um rei a ponto de dar ordem de assalto a uma praça cercada, perguntam-se por onde começar a ofensiva, desejando em simultâneo, causar estragos por toda a parte! (CARTER, 1940, pp. 935 e 956).

No que comer Hugo reprova o uso de alimentos caros e esquisitos ou preparados com requinte e exotismo, havendo sempre aqueles que se queixam de doenças imaginárias a necessitar de cozinhados à parte ou de alimentos invulgares. Outros há que exigem cuidados excessivos na sua preparação, inventando mil necessidades de cozeduras, frituras e temperos e, quais mulheres grávidas, não param de exigir comidas ora moles, ora duras; ora mais frias, ora mais quentes; bem cozidas, mal guisadas, grelhadas ao de leve, mais apimentadas, com menos alho, com pouco sal!

Também neste ponto a versão de Alcobaça é precioso testemunho de adaptação à época da sua tradução quando refere: «E ora se lhes entulham pimenta, ora alhos, ora cominhos, ora canela, ora açafrão, ora cravos e outros muitos condimentos» (CARTER, 1940, 1. 1008; 1110).

O quadro de riso que Hugo pinta está bem próximo daquele outro que, por essa mesma altura, o cisterciense S. Bernardo, com não menos mestria, traçava em Claraval, na carta ao seu confrade e amigo, o abade Guilherme de Thierry, em que se lamentava da esquisitisse gulosa de alguns monges, pouco enfastiados, acerca da comida, quando, depois de quatro ou cinco pratos, não tinham diminuído o apetite e, para continuar, virando-se e revirando-se na mesa, exigiam do cozinheiro ovos bem batidos, mal passados, fritos, cozidos ou estrelados, ora simples, ora recheados ou mexidos (CLARAVAL, 1997, pp. 51-53) ${ }^{24}$ !

Sobre a maneira de comer Hugo aproveita, de novo, através de traços derrisórios, para reprovar a má conduta de alguns e para editar regras de boa educação à mesa. Ensinando como se deve comer, sem meter directamente as mãos no prato nem as limpar depois ao vestuário, ${ }^{25}$ comer sempre devagar, sem falar, sem pressas e 
mastigando bem os alimentos, sem querer impor, indiscriminadamente, a quantidade de que cada um precisa, pois cada qual tem um corpo e um organismo com necessidades diferentes $^{26}$. Reprova os que, do dizer alcobacense, «estroncam os dedos e andam pescando as verças com eles, metendo-os no caldo, ataa aos artelhos»! Para concluir que os Regrantes deviam corar pela necessidade de ter que lhes dizer estas coisas, mas que a vergonha era antes em ouvi-las, por parte daqueles que as praticavam.

Hugo não se limita a condenar o prazer e o luxo alimentar. Não ignorando que só pelo «rigor da disciplina» é possível pôr freio à glutonaria, constrói o seu complexo sistema de prescrições e interditos para moderar os comportamentos dos noviços: propósitos, gestos, atitudes e mesmo o comportamento à mesa (CASAGRANDE; VECCHIO, 2003, p. 221).

Observe-se, de novo, como para ele, retomando uma velha tradição, o ideal da justa medida é uma condição do bem moral ou da ética. Mas isso aqui não é suficiente e o propósito educativo é ampliado. Aproveita para inculcar o uso de normas de disciplina de higiene e limpeza, «munde et temperate». Sabendo nós como já então em S. Victor, à mesa, cada um dispunha do seu guardanapo individual [manutergia], insiste na proibição do uso directo das mãos (nudis articulis) em contacto com a comida que vai ser de outros, e na sua contenção na própria, escandalizando-se com o que alguns deixam cair dos pratos sobre a mesa ou de como molham os dedos nos copos ou os metem na boca para desatulhar os dentes!

Para chegar à Sabedoria, Hugo de S. Victor propusera, primeiro, a ciência, escrevendo o Didascalicon, uma arte de ler ao alcance de todos, reorganizando os saberes tradicionais e modernizando-os com a inclusão das artes mecânicas e, sem nada deixar de fora, ampliando o programa de estudos das escolas europeias. Para a elite mais culta e que encetava outra etapa formativa, apontava os meios de formar educadores e divulgadores nos meios urbanos que já então eram os polos motores de evolução da sociedade.

Como linhas de força do seu método mostrara como na república do corpo, o ideal ético da harmonia e o das boas maneiras se alcançam: a oposição interior/exterior, dentro/fora deve ser resolvida pela subordinação da segunda à primeira; a ideia de «função» mostra como cada órgão deve desempenhar o seu ofício; o ideal de justa medida (modus, modestia, temperantia), como já no século VI, explicara 
S. Martinho de Dume ou de Braga, é fundamento do verdadeiro humanismo (ROMAGNOLI, 1991, pp. 48-49).

Ao propor este ideal de comportamentos, de boas maneiras, para os seus noviços Mestre Hugo de S. Victor criou um quadro de disciplina verdadeiramente universal: os séculos seguintes mostrariam como estas normas acabaram por ser adoptadas, primeiro, nos meios monásticos, depois, nos clericais e na corte (a courtoisie é uma das novidades do século XII); seguidamente, na cidade (onde a urbanidade distingue acima dos outros, dos rústicos), vindo, progressivamente, a tornar-se normas comuns de civilidade e etiqueta, isto é, normas gerais de civilização em todo o Ocidente (KNOX, 1991, pp. 107-135).

Como referiu J. Le Goff,

A história das maneiras dá ao estudo desses objectos, demasiado vagos que são os sentimentos ou as mentalidades, a base sólida de uma história dos valores (...). E requer ser ligada com a história política renovada, uma história do poder que nunca é, mais eficaz do que lá onde são em definitivo sagrados e de onde se difundem os códigos das boas maneiras: o mosteiro, o castelo, a cidade, a corte, a família ou a escola - outras tantas etapas de difusão das regras de conduta (LE GOFF, 1991, pp. 09-10).

Conhecendo, copiando e ensinando as obras de Hugo de S. Victor, Portugal mostrava, através dos seus centros culturais dianteiros de Coimbra, Lisboa e Alcobaça que, nos séculos XII-XV, era parte integrante desse vasto movimento europeu de formação de valores e boas maneiras de que haveria de nascer o mundo moderno, o nosso mundo.

\section{KNOWLEDGE AND WISDOM: THE POTENTIALITY IF THE CIRCUMSTANCES IN AN EDUCATION BOOK OF THE 12th CENTURY}

ABSTRACT: Several works of Parisian master, Hugh of Saint Victor (1096-1141), canon regular of that abbey, were known and studied in Portuguese monasteries of S. Vicente de Fora of Lisbon and Santa Cruz of Coimbra, since the thirteenth century. Thus, the succinct treatise De Institutione Novitiorum was destined to form future regulars at traditions and mores of St. Augustine's Order. It is not a mere spiritual text, but also a kind of second edge of a diptych of Didascalicon, previous work. Short manual of good manners or "art of living", it had general concerns of anthropological and civic humanism, rules of good manners, understood as the foundation of a state of perfection of true Christian religious life. However, we have to consider always the circumstances in which the process takes place. These ideas originated in France and transplanted to medieval Portugal continued to serve as a training guide and appeared, 
afterwards molded into the mindset of regulars in Brazil, as D. Thomaz da Encarnação, bishop of Olinda-Recife (1774-1784), educated man and reformer of his diocese.

Keywords: Hugh of Saint Victor, wisdom, discipline

SABER Y SABIDURÍA: EL POTENCIAL DE LAS CIRCUNSTANCIAS EN UN MANUAL DE EDUCACIÓN DEL SIGLO XII

RESUMEN: Varias obras del maestro parisino Hugo S. Victor (1096-1141), canónigo reglante en aquella abadía, eran conocidas y estudiadas en los monasterios portugueses de San Vicente de Fora, en Lisboa, y Santa Cruz de Coimbra, desde el siglo XIII. Así, el breve tratado De Institutione Novitiorum se destinaba a formar a los futuros reglantes en las tradiciones y costumbres de la Orden de San Agustín. Ese no es simplemente un texto espiritual, sino una especie de continuación de un díptico de Didascalicon, obra anterior. Pequeño manual de buenas maneras o del 'arte de vivir', tenía preocupaciones generales a respecto del humanismo antropológico y cívico, de los buenos modales, entendidos como el fundamento del estado de perfección de la verdadera vida religiosa cristiana. Sin embargo, hay que atender a las circunstancias en las que se ejecuta el proceso. Estas ideas, nacidas en Francia y trasplantadas para el Portugal medieval, siguen como guías de formación y llegaron, más tarde, moldeadas en la forma de pensar de los pertenecientes a la Orden de Santa Cruz de Coimbra en Brasil, como D. Thomaz da Encarnação, obispo de Olinda-Recife (1774-1784), hombre culto y reformador de su diócesis.

Palabras clave: Hugo de S. Victor, disciplina, sabiduría.

\section{NOTAS}

1 A Legenda Prima é anónima. Os historiadores atribuem-na, sem dúvidas, a um autor franciscano (Tomás de Celano? Tomás de Pavia? João Gil de Zamora?) que a teria redigido a pedido do papa Gregório IX (1227-1241), logo a seguir à canonização de S. António, ocorrida em 30 de Maio de 1232.

2 «Hii sunt libri monasterii Sancti Vincencii». Embora autónomos, os dois mostei ros regrantes estavam muito ligados entre si, tendo S. Vicente sido fundado por alguns cónegos procedentes de Coimbra que continuavam a considerar como uma espécie da casa-mãe e com quem mantinham muitos contactos de filiação.

${ }^{3} \mathrm{O}$ rol dos manuscritos emprestados estava registrado no verso do último fólio do códice 34 de Santa Cruz.

${ }^{4} \mathrm{Na}$ Vita Tellonis, transcreve-se uma carta do prior D. Teotónio que o presbítero Pedro ia levar a Avinhão, onde era enviado com esses objectivos, logo após a morte do primeiro dos fundadores, em 1136. Pouco depois, segundo a Vita S. Theotonii, outros dois cónegos, Domingos e Pedro, dirigiam-se à mesma canónica do sul de França, para que aí lhes fosse permitido copiar outros textos fundamentais da vida regrante.

${ }^{5}$ Embora seja pouco segura a fonte que, directamente, serve de apoio para documentar a criação de bolsas régias de 400 morabitinos, em 1190, são mais seguras as que nos mostram como eram enviados estudantes para «apud Gallias», «in partibus Galliae» e mesmo Paris. Havia, aliás, um precedente pois um dos fundadores da canónica, D. João Peculiar, antes de ser mestre-escola da catedral conimbricense teria feito os seus estudos em Paris e vinha habilitado com a licentia docendi.

${ }^{6}$ O texto, Disciplina dos Monges aparece inserido numa miscelânea, fls. 148-180, verdadeiramente, fls. 161-176, com vários outros e foi traduzido pelo monge cisterciense do mosteiro do Bouro, Fr. Francisco de Melgaço. Da obra vitorina, em 21 capítulos, foram vertidos os doze últimos referentes à disciplina, 
quase na totalidade. Não tomaremos aqui em conta as questões paleográficas, remetendo o leitor para Henry Hare Carter e Mário Martins.

${ }^{7}$ A evocação de Ovídio no parágrafo anterior, Epistulae ex Ponto, 1, 3, é sinal do seu conhecimento da sua estima pelos clássicos como este, que toma como suas fontes.

${ }^{8}$ Sobre esta viragem e seu significado cultural vide o brilhante estudo de CHENU, M.-D., «Civilisation urbaine et théologie. L'école de Saint-Victor au XII ${ }^{\mathrm{e}}$ siècle», Annales. Économies, Sociétés, Civilisations, 29. ${ }^{\text {e }}$ année, n. 5 (1974).

${ }^{9}$ Bastaria recordar a invocação que faz de Platão, Cícero, Tito Lívio, Horácio, Virgílio ou Ovídio para o colocarmos entre os construtores do «renascimento do século XII». Veja-se ainda G. PARÉ, A. BRUNET, P. TREMBLAY, La Renaissance du XII ${ }^{e}$ siècle. Les Écoles et l'Enseignement. Paris-Ottawa: J. Vrin-Institut d'Études Médiévales, 1933.

${ }^{10} \mathrm{Sl}$. LIV, 10

${ }^{11}$ Entenda-se, naturalmente, o caso pessoal, como referência a Guilherme de Champeaux, fundador dos Regrantes parisienses, em 1108, e que fora a antes mestre de Abelardo, com quem tivera disputas acérrimas. «D'Abélard a un Ami», in Abélard et Heloise Correspondance, ed. De Paul Zumthor, Paris, Union Génerale d'Éditions, 1979, pp. 44 s. Pedro Abelardo via no conflito de ideias um meio de progredir em direcção à verdade.

${ }^{12}$ Autores como SCHMITT, J.-Cl., partindo da análise interna do texto de De Institutione Novitiorum, pretendem concluir que ele faria parte de um tríptico dedicado à ciência, disciplina e virtude, estando aqui tratados apenas os dois primeiros temas. O autor sugere que outra obra de Hugo, De Quinque Septenis, que circula separadamente, poderia bem ser essa parte que falta. Os especialistas e editores mais recentes das obras de Hugo de S. Victor rejeitaram essa ideia.

${ }^{13}$ Mestre Hugo coloca-se, neste caso, nas antípodas do programa da dialéctica escolástica ou de outras «escolas de ignorância» que, buscando rentabilidade e utilitarismo antepunha a tudo a função de alcançar na sociedade promissoras carreiras de poder e rendimento material. Foi a esses que um seu quase contemporâneo, também humanista, João de Salisbúria (115-1180), utilizando o nome de um dos detractores do poeta Virgílio, chamou de «cornificianos». PARÉ, G., BRUNET, A., TREMBLAY, P., La Renaissance du XII siècle Les Écoles et l'Enseignement, Paris-Otawa, J. Vrin et Institute d'Études Médiévales, 1933.

${ }^{14}$ Hugo define «esta ciência» como «tudo aquilo que diz respeito ao facto de viver recta $e$ honestamente»; «é a da verdadeira discrição»; «pela ciência se vai à disciplina»; «a ciência adquire-se, em parte pela razão, em parte pela doutrina, em parte pelo exemplo, em parte pela meditação da Escritura e, em parte, pela frequente inspecção das próprias obras e costumes».

${ }^{15} \mathrm{O}$ humanismo medieval de Hugo é patente em dois sentidos: pela nova visão do homem e pela invocação das autoridades clássicas em seu auxílio: Platão, Cícero, Virgílio, Ovídio, Horácio, Séneca.

${ }^{16}$ Tenha-se em atenção que, no séc. XII, a população claustral vitorina era essencialmente de origem aristocrática e muitos professavam já adultos, com velhos hábitos inveterados que lhe custava largar.

${ }^{17}$ A única cópia que nos chegou é de princípios do século XV.

18 «gestus est modus et figuratio membrorum corporis ad onmem agendi et habendi modum». Note-se como os tradutores desta edição discordam da leitura e versão feitas por Schmitt.

${ }^{19}$ Bem Sirac, 19, 29-30.

${ }^{20}$ Prov. 6, 12-13.

${ }^{21}$ Seguiremos muito de perto e seremos devedores, neste domínio, o exímio estudo destas duas autoras italianas que, vivamente, agradecemos.

${ }^{22}$ Nos mosteiros, em tempos de silêncio, certos gestos substituíam a palavra, como acontecia em Alcobaça. Veja-se a este respeito um estudo de José Rivair.

${ }^{23}$ Neste ponto Hugo segue à letra os preceitos consignado no Liber Ordinis de S. Victor, no c. 35 , «De refectorio», oc., p. 171.

${ }^{24} \mathrm{O}$ apresentador do texto data-o de cerca de 1124-1125, quando o de Hugo não seria muito posterior, como vimos.

${ }^{25}$ Uma passagem do Liber Ordinis de S. Victor, confirma-nos, já então, o uso de guardanapos [manutergia] à mesa, na abadia, recomendando que fossem mudados cada duas semanas.

${ }^{26}$ Também neste pormenor Hugo segue muito de perto a "Regra de S. Agostinho»: "distribuatur unicuique (...) victus et tegumentum non aequaliter omnibus, quia non aequaliter valetis omnes, sed potius unicuique sicut opus fuerit», Praeceptum, 1, 3, PL 32, col. 1378 D.

\section{FONTES}


Catálogo dos Códices da Livraria de Mão do Mosteiro de Santa Cruz de Coimbra na Biblioteca Pública Municipal do Porto, Porto, BPMP, 1997, pp. 340-341.

CLARAVAL, Bernardo de, Apologia para Guilherme abade, apres., trad. e notas de Geraldo Coelho Dias. Porto: Fundação Eng. ${ }^{\circ}$ A. de Almeida, 1997.

Petrus Abelardus, «Epistola contra quemdam canonicum regularem qui monasticum ordinem deprimebat et suum illi anteferebat», PL 178, cols. Petrus Abelardus, «Epistola contra quemdam canonicum regularem qui monasticum ordinem deprimebat et suum illi anteferebat», PL 178, cols.

POIREL, D., H. ROCHAIS et P. SICARD (ed.), L'Oeuvre de Hugues de Saint- Victor 1, De Institutione novitiorum, De virtute orandi, De laude caritate, De arrha animae, Brepols, 1997, Introduction.

P. SICARD, Hugues de Saint-Victor et son École, oc., pp. 189 s.

S. VICTOR, Hugo de, L'Art de lire, Didascalicon, introduction, traduction et notes par Michel Lemoine, Paris, Cerf, 1991, VI, 3, p. 212. Ed. portuguesa, Didascálicon, Da arte de ler (edição bilingue), introdução e tradução de António Marchionni, Petrópolis, Editorial Vozes, 2001, p. 239.

S. VICTOR, Hugo. De Instituitione, 1997.

\section{REFERÊNCIAS}

BYNUM, Caroline. The Spirituality of Regular Canons in the Twelfth Century: a New Approach. Medievalia et Humanistica, new series, n. 4, 1973.

CARTER, Henry Hare. Paleographical Edition of an Old Portuguese Version of the Rule of Saint Bernard (Codex Alcobacensis 200). In: Publications of the Modern Language Association of America, 55, New York, 1961.

CHÂTILLON, Jean. Le Mouvement Canonial au Moyen Age. Brepols: 1992.

CRUZ, A. S. Cruz de Coimbra na cultura portuguesa medieval, Porto, BPMP, 1963.

GAMA CAEIRO, Francisco da. Santo António de Lisboa. Introdução ao Estudo da Obra Antoniana, vol. I. Lisboa: 1967.

CASAGRANDE, Carla; VECCHIO, Silvana. Histoire des péchês capitaux au Moyen Age. Paris: Aubier, 2003. Les Péchés de la Langue. préf. Le GOFF, J., Paris: Éditions du Cerf, 2007.

CASAGRANDE, Carla. Prediche alle Donne del secolo XIII. Milano: Bompiano, 1978 
DUBY, Georges. As Três Ordens ou o Imaginário do Feudalismo. Lisboa: Estampa, 1982.

FALQUE, E. Le geste et la parole chez Hugues de Saint-Victor: l'institution des novices. Révue de Sciences Philosophiques et Théologiques, 95, 2011.

JOCQUÉ, Luc. Les structures de la population claustrale dans l'Ordre de Saint-Victor au XII siècle. Un essai d'analyse du Liber Ordinis. L'Abbaye Parisienne de SaintVictor au Moyen Age. Paris-Thurnhout: Brépols, 1991, pp. 53-95.

KNOX, D. "Disciplina" The monastic and clerical origins of european civility. In: MONFASANI, J., MUSTO, R., (ed.). Renaissance Society and Culture. Essays in Honor of E. F. Rice Jr. New York: Italica Press, 1991, pp. 107-135.

LE GOFF, Jacques. Préface. In:ROMAGNOLI, Daniela (dir.). La Ville et la Cour Des bonnes et des mauvaises manières. Paris: Fayard, 1991, pp. 9-10.

MARTINS, Mário, Disciplina dos Monges, Brotéria, n. ${ }^{\circ} 72$ (1940).

RIVAIR, José. Disciplina do silêncio e comunicação gestual: os 'signa loquendi' de Alcobaça. Signum, v. 5 (2003), pp. 88-107.

ROMAGNOLI, Daniela (dir.). La Ville et la Cour Des bonnes et des mauvaises manières. Paris: Fayard, 1991.

SCHMITT, Jean-Claude. La Raison des Gestes dans l'Occident Médiéval. Paris: Gallimard, 1990.

SICARD, P. Savoir et sagesse dans une école médiévale: le cas de Saint-Victor de Paris. In: SCHAER, Roland (dir.). Tous les Savoirs du Monde. Bibliothèque National de France: Flammarion, 1996.

VERGER, Jacques. Abélard et les milieux sociaux de son temps. In: Abélard en son Temps. Actes du colloque international organisé à l'occasion du 9. ${ }^{e}$ centenaire de la naissance de Pierre Abélard (14-19 Mai 1979). Paris: Les Belles Lettres, 1981. 